\title{
Projected Changes in Intense Precipitation over Europe at the Daily and Subdaily Time Scales*
}

\author{
ENRICO SCOCCIMARRO \\ Istituto Nazionale di Geofisica e Vulcanologia, and Centro Euro-Mediterraneo sui Cambiamenti Climatici, Bologna, Italy \\ GABRIELE VILLARINI \\ IIHR-Hydroscience and Engineering, The University of Iowa, Iowa City, Iowa \\ MARCELLO VICHI \\ Department of Oceanography, University of Cape Town, Cape Town, South Africa \\ Matteo Zampieri, Pier Giuseppe Fogli, AND Alessio Bellucci \\ Centro Euro-Mediterraneo sui Cambiamenti Climatici, Bologna, Italy \\ SILVIO GUALDI \\ Istituto Nazionale di Geofisica e Vulcanologia, and Centro Euro-Mediterraneo sui Cambiamenti Climatici, Bologna, Italy
}

(Manuscript received 13 November 2014, in final form 7 May 2015)

\begin{abstract}
Heavy precipitation is a major hazard over Europe. It is well established that climate model projections indicate a tendency toward more extreme daily rainfall events. It is still uncertain, however, how this changing intensity translates at the subdaily time scales. The main goal of the present study is to examine possible differences in projected changes in intense precipitation events over Europe at the daily and subdaily (3-hourly) time scales using a state-of-the-science climate model. The focus will be on one representative concentration pathway (RCP8.5), considered as illustrative of a high rate of increase in greenhouse gas concentrations over this century. There are statistically significant differences in intense precipitation projections (up to $40 \%$ ) when comparing the results at the daily and subdaily time scales. Over northeastern Europe, projected precipitation intensification at the 3-hourly scale is lower than at the daily scale. On the other hand, Spain and the western seaboard exhibit an opposite behavior, with stronger intensification at the 3-hourly scale rather than the daily scale. While the mean properties of the precipitation distributions are independent of the analyzed frequency, projected precipitation intensification exhibits regional differences. This finding has implications for the extrapolation of impacts of intense precipitation events, given the daily time scale at which the analyses are usually performed.
\end{abstract}

\section{Introduction}

Examination of whether or not precipitation is projected to intensify over the twenty-first century represents a topic

\footnotetext{
* Supplemental information related to this paper is available at the Journals Online website: http://dx.doi.org/10.1175/JCLI-D-14-00779.s1.

Corresponding author address: Enrico Scoccimarro, Centro Euro-Mediterraneo sui Cambiamenti Climatici (CMCC), V.le A. Moro, 44, 40127 Bologna, Italy.

E-mail: enrico.scoccimarro@ingv.it
}

that has received a large amount of attention in the scientific community because of the potential implications in terms of flood hazard. Future climate scenario simulations performed with standard protocols [CMIP3 (Meehl et al. 2007) and CMIP5 (Meehl and Bony 2012; Taylor et al. 2012), among others] allow investigations of the changes in meteorological parameters at different time scales. Most of the analyses of the statistics of intense precipitation events are based on daily or monthly data from both global oceanatmosphere coupled general circulation models (CGCMs) and regional climate models (RCMs). Many investigations inspecting projected changes of climatological and/or 
intense/extreme precipitation events over Europe rely on daily climate model data (e.g., Wetherald and Manabe 1999; Kharin and Zwiers 2000; Hegerl et al. 2004; Kharin et al. 2007; Hegerl et al. 2007; Kiktev et al. 2007; Min et al. 2009; Seager et al. 2012). Much less is known, however, about changes in extreme precipitation events at subdaily scales (Lenderink and van Meijgaard 2008; Jones et al. 2010; Hanel and Buishand 2010; Kendon et al. 2014; Ban et al. 2014; Chan et al. 2014a), with the existing results pointing to an overall greater increase in subdaily rather than daily intense precipitation events in a warmer climate (Kendon et al. 2014). A super-Clausius-Clapeyron scaling (Trenberth et al. 2003; Molnar et al. 2015) at the subdaily scale has also been found during the summer (Lenderink and van Meijgaard 2008) based on observational studies. However, the spatial variability of the aforementioned differences is still uncertain.

Hourly extremes are generally dominated by convective precipitation. Convective precipitation tends to be of short duration ( $1-4 \mathrm{~h}$ ), while long-duration ( $12 \mathrm{~h}$ to 3 day) extremes tend to have larger spatial scales and are often associated with synoptic weather systems (Chan et al. 2014b). The main goal of the present study is to compare projected changes in intense precipitation events at the daily and subdaily scales. The relevance of this analysis also stems from the evidence that not only flood events (more related to sustained intense precipitation) impact our society, but also intense events with a few hours' duration can have a great societal impact. Prominent examples are the extreme rainfall events registered over Boscastle (United Kingdom) in August 2004 (Burt 2005) and over Sardinia (Italy) in November 2013. To address this issue we use a highresolution, fully coupled general circulation model, developed to provide climate projection data for the Fifth Assessment Report of the Intergovernmental Panel on Climate Change (IPCC; Stocker et al. 2013). Changes in intense precipitation statistics are investigated at daily and 3-hourly time scales, following one representative concentration pathway (i.e., RCP8.5; Riahi et al. 2011) featuring the highest rate of increase in greenhouse gas concentrations for the twenty-first century among the RCPs considered in the latest IPCC report.

The paper is organized as follows: Section 2 describes the model, together with a short description of the climate simulations and the methodology. Section 3 presents the results of the analyses, while section 4 summarizes the main points of the study and concludes the paper.

\section{Data and methods}

\section{a. Model and simulations}

The model we employ is the Centro Euro-Mediterraneo sui Cambiamenti Climatici coupled atmosphere-ocean general circulation model (CMCC-CM; Scoccimarro et al. 2011; Bellucci et al. 2013), which has been implemented and developed in the framework of the phase 5 of the Coupled Model Intercomparison Project (CMIP5; Meehl and Bony 2012). The model is an evolution of the Istituto Nazionale di Geofisica e Vulcanologia (INGV) Scale Interaction Experiment [SINTEX-G (SXG); Gualdi et al. 2008; Bellucci et al. 2008] and the CMCC Earth System Model (Fogli et al. 2009; Vichi et al. 2011). The global ocean component is OPA 8.2 (Madec et al. 1998), in its ORCA2 global configuration. The horizontal resolution is $2^{\circ} \times 2^{\circ}$ with a meridional refinement near the equator, approaching a minimum $0.5^{\circ}$ grid spacing. The model has 31 vertical levels, 10 of which lie within the upper $100 \mathrm{~m}$. ORCA2 also includes the Louvain-La-Neuve (LIM) model for the dynamics and thermodynamics of sea ice (Fichefet and Morales-Maqueda 1999). Ocean physics include a free-surface parameterization (Roullet and Madec 2000) and the Gent and McWilliams (1990) scheme for isopycnal mixing.

The atmospheric model component is ECHAM5 (Roeckner et al. 2003) with a T159 horizontal resolution, corresponding to a Gaussian grid of about $0.75^{\circ} \times 0.75^{\circ}$. This configuration has 31 hybrid sigma-pressure levels in the vertical and a $10-\mathrm{hPa}$ top. The parameterization of convection is based on the mass flux concept (Tiedtke 1989), modified following Nordeng (1994). Moist processes are treated using a mass-conserving algorithm for the transport (Lin and Rood 1996) of the different water species and potential chemical tracers. The transport is resolved on the Gaussian grid. A more detailed description of the ECHAM model performance can be found in Roeckner et al. (2006).

The communication between the atmospheric model and the ocean models is carried out with the Ocean Atmosphere Sea Ice Soil version 3 (OASIS3) coupler (Valcke 2006). At every coupling step (set to $160 \mathrm{~min}$ ), heat, mass, and momentum fluxes are computed and provided to the ocean model by the atmospheric model. Sea surface temperature, sea ice cover and thickness, and sea surface velocities are provided to the atmospheric model by the ocean model. No flux corrections are applied to the coupled model.

Two periods are analyzed: 1) the period 1986-2005 (labeled as PRESENT), corresponding to the last part of the "historical" CMIP5 simulation, and 2) the period 2081-2100 (labeled as FUTURE), run under the highend RCP8.5 scenario (Riahi et al. 2011). Both the summer [June-August (JJA)] and winter [DecemberFebruary (DJF)] seasons are considered, but a major attention is devoted to the winter season. During this season, the so-called atmospheric rivers (AR) have been identified as major agents for extreme precipitation events (Lavers et al. 2013, Hagos et al. 2015). The special 


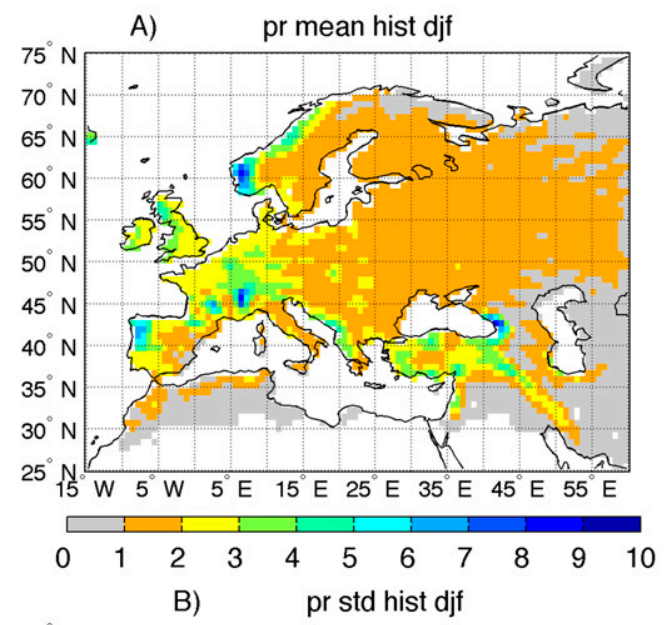

C) \% change rcp85 wrt hist of the averaged precip djf

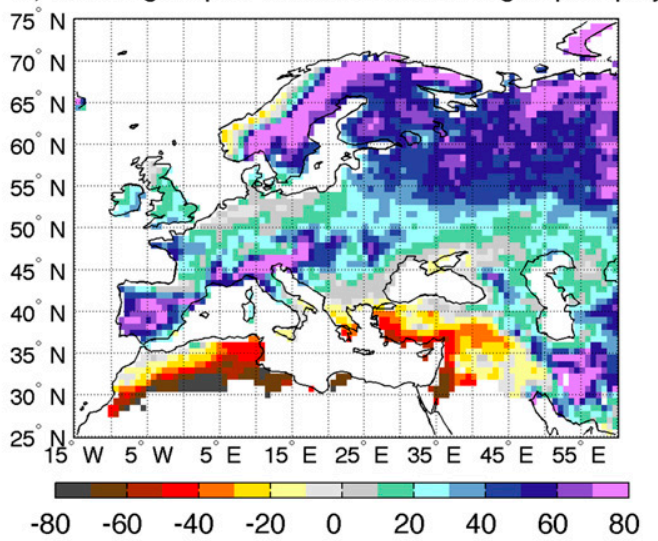

D) \% change rcp85 wrt hist of the precip std djf
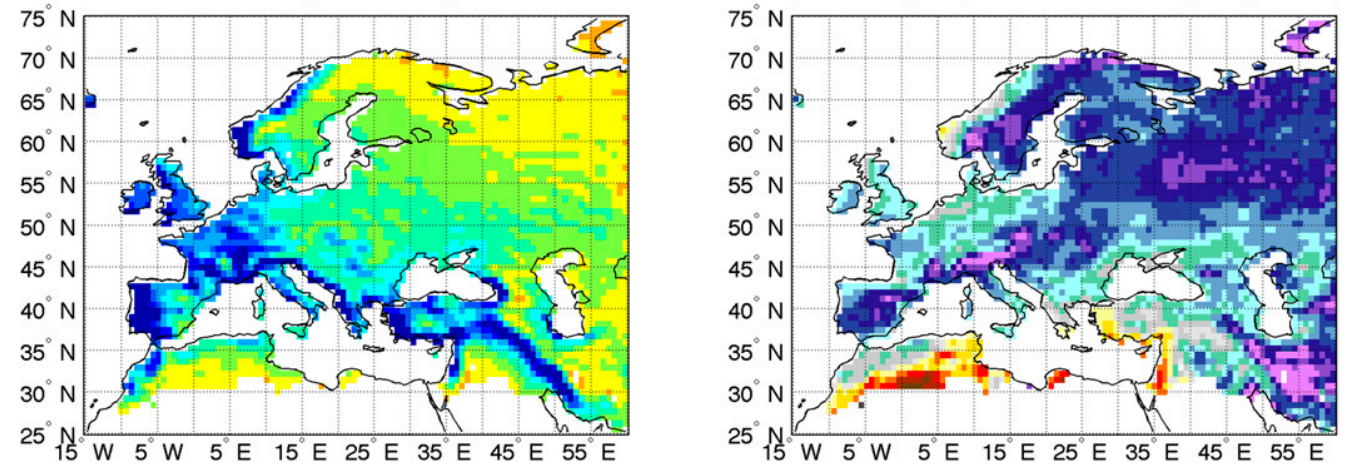

FIG. 1. DJF (a) precipitation climatology and (b) standard deviation as resulting from the PRESENT climate simulation using 3-hourly data (in mm day ${ }^{-1}$ ). (c),(d) The relative changes in FUTURE (rcp85) with respect to the PRESENT (hist) run (in \%). White patterns over land indicate regions with precipitation lower than $0.2 \mathrm{~mm} \mathrm{day}^{-1}$.

focus on the winter season is justified by the wellestablished capability of current climate models in simulating extreme events over Europe during this season, unlike what is found during summer (Toreti et al. 2013). The atmospheric grid resolution used in most climate models is only convection-permitting and does not resolve the convection processes explicitly. The use of convection parameterizations is a known source of model error, especially during summer over Europe, when deep convection is the main source of extreme precipitation events (Ban et al. 2014, Kendon et al. 2014).

The historical simulation is performed forcing the model with observed concentrations of greenhouse gases, aerosols, ozone, and solar irradiance, starting from an arbitrary state of a quasi-equilibrium control run. The RCP8.5 scenario follows a rising radiative forcing pathway leading to $8.5 \mathrm{~W} \mathrm{~m}^{-2}$ in 2100 .

\section{b. Methods}

At each grid point, the distribution of precipitation events is evaluated for the two target seasons (JJA and DJF) and 20-yr PRESENT and FUTURE periods, over
Europe, using both daily and 3-hourly accumulation time windows. It is well known that intrinsic climate fluctuations occur not only on interannual to decadal time scales but also over periods as long as $50 \mathrm{yr}$ (Deser et al. 2012), but the 20-yr time window considered here is deemed sufficient to sample the internal temporal variability over the investigated region (Schindler et al. 2015). As a result, four different distributions (two seasons and two 20-yr periods) are obtained, and the corresponding 90th percentiles (90p) are calculated. The 90p threshold is then used to define a "heavy precipitation" event (Scoccimarro et al. 2013). Dry events (here defined as lower than $0.2 \mathrm{~mm} \mathrm{day}^{-1}$ precipitation events) were not considered when computing the percentiles.

To assess whether 3-hourly intense events fall within daily intense events, the list of days with intense events was finally computed for every model grid point using both daily and 3-hourly time series.

\section{Results}

The PRESENT climate precipitation activity over Europe based on this model (Scoccimarro et al. 2015) 

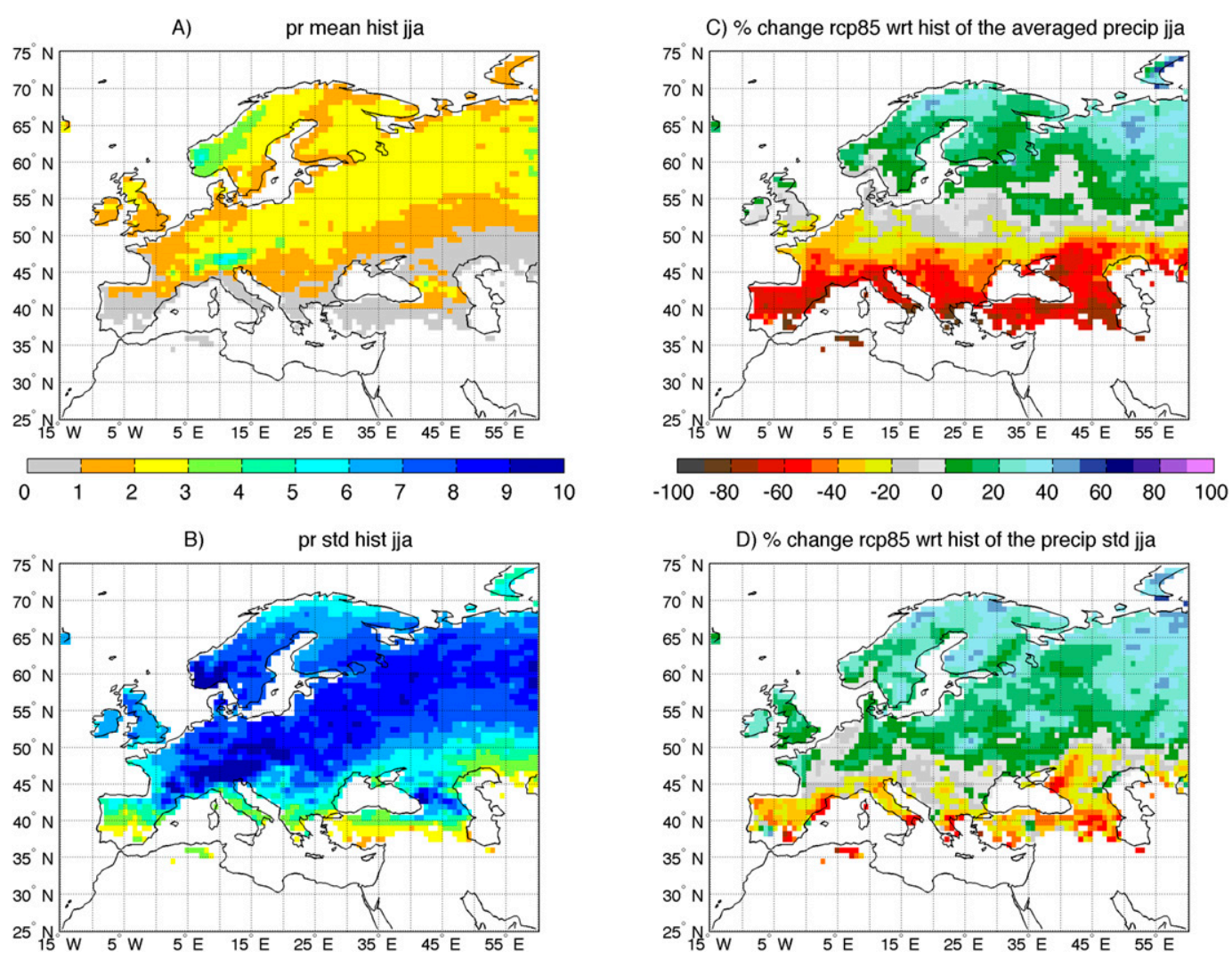

FIG. 2. As in Fig. 1, but for JJA.

was shown to be in close agreement with GPCP observations (Bolvin et al. 2009) both in terms of climatology and intense events statistics during winter and summer. Many studies focusing on European precipitation's future changes project an increase in the annual climatological precipitation over northern Europe and a decrease over the Mediterranean area, especially during summer (e.g., Heinrich and Gobiet 2011; Nikulin et al. 2011; Smiatek et al. 2009; Scoccimarro et al. 2015). Despite the uncertainties affecting the amplitude of the models' responses, there is a high degree of cross consistency in the sign. The CMCC-CM model results confirm these findings for both winter (Fig. 1) and summer (Fig. 2). In particular, mean precipitation over northeastern Europe is projected to increase up to $70 \%$ in winter (Fig. 1c), where also the variability is projected to increase markedly (Fig. 1d). This increase is confirmed, although to a lesser extent, by multimodel ensemble averages of CMIP5 simulations (e.g., Fig. 2 in Scoccimarro et al. 2015). It is interesting to note that the coefficient of variation (the standard deviation normalized by the mean) for precipitation is always greater than one: the standard deviation exceeds the average precipitation during both seasons, in particular in the southern part of Europe during the winter season (Fig. 1, left panels).
In terms of heavy precipitation (90p; Fig. 3 for DJF) the model suggests an increase in the FUTURE period when compared to the PRESENT over almost the entire domain, in agreement with previous works (e.g., Trenberth et al. 2003; Meehl et al. 2005; Chou et al. 2009; Scoccimarro et al. 2013). This occurs in both seasons (see Fig. S1 in the supplemental material for JJA projections) although the projected 90p changes are more evident during the winter than during the summer. In summer, only the southern part of the Mediterranean domain shows a projected reduction of intense precipitation events in the future climate, consistent with previous RCMs' results (Rajczak et al. 2013). It is worth noting, however, that the use of parameterization to represent convection is a strong limitation, especially in representing summer precipitation over Europe. The general increase of the $90 \mathrm{p}$ values is consistent with a larger moisture-holding capacity of the warmer air, contributing to greater moisture convergence (e.g., Tebaldi et al. 2006; Giorgi et al. 2011).

The time window used to accumulate the precipitation field in the analyses (i.e., daily or 3-hourly) affects the spatial distribution of the projected changes of the 90p, particularly during winter (Figs. 3c,d), whereas a much weaker dependency is found in the summer (Fig. S1 in 


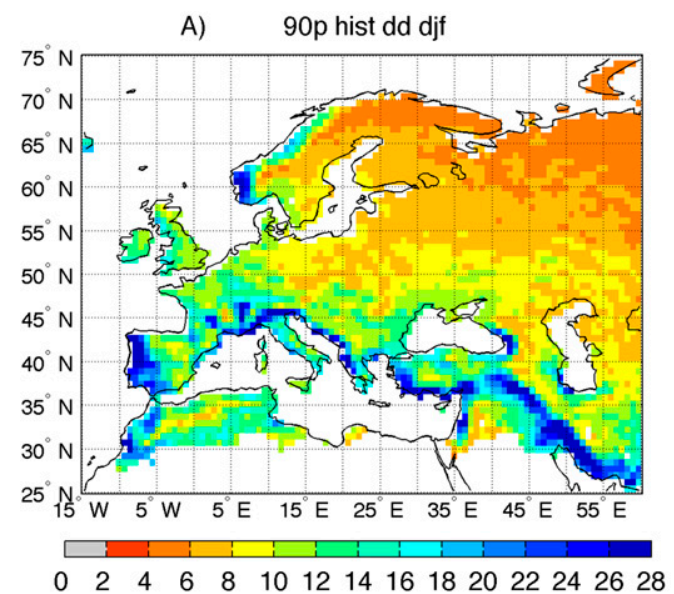

B) $\quad 90 \mathrm{p}$ hist $3 \mathrm{~h}$ djf

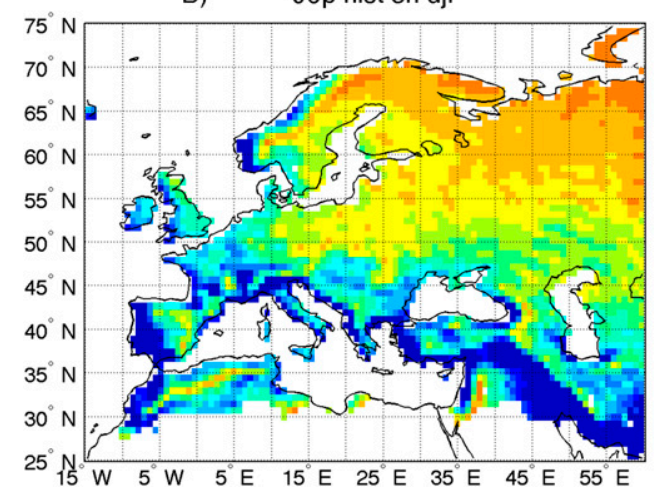

C) 90 p RCP $8.5 \%$ change dd based wrt HIST djf

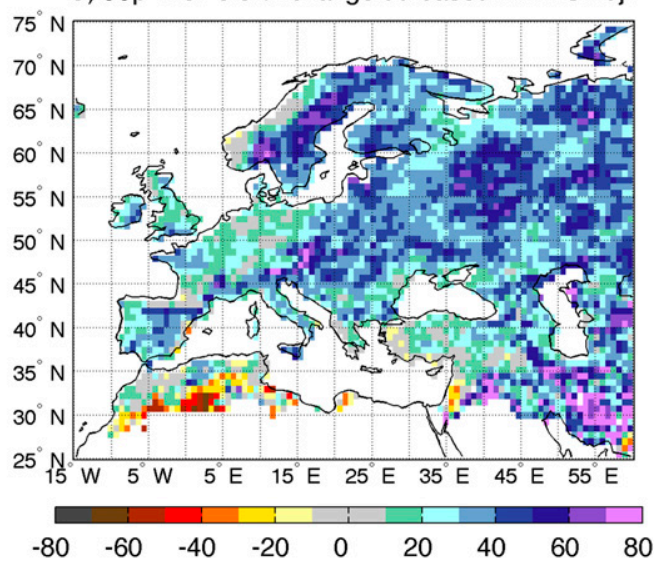

D) $90 \mathrm{p}$ RCP $8.5 \%$ change $3 \mathrm{~h}$ based wrt HIST djf

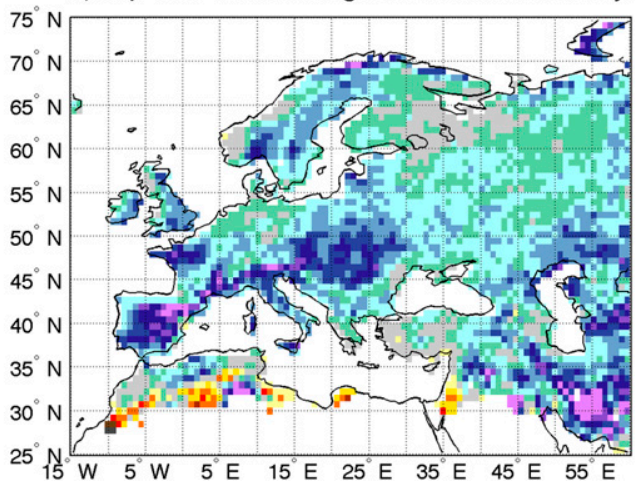

FIG. 3. Maps showing the 90th percentile (90p) of DJF precipitation computed at (top) daily (dd) and (bottom) 3-hourly (3h) time scales, showing (a),(b) the historical (1986-2005) 90th percentile and (c),(d) the percentage change in the FUTURE (rcp85) run (2081-2100) with respect to the PRESENT (HIST) run. Units are mm day ${ }^{-1}$ for (a) and (b) and \% for (c) and (d). White patterns over land indicate regions with precipitation lower than $0.2 \mathrm{~mm} \mathrm{day}^{-1}$.

the supplemental material). Over the northeastern part of the study region (including northeastern Europe and western Russia; hereafter referred as the NE domain) the projected changes in $90 \mathrm{p}$ are lower at the 3-hourly than at the daily time scales (Figs. 3c,d). Notably, Kendon et al. (2014) found a similar behavior over the southern United Kingdom when comparing hourly to daily precipitation. The values of the $90 \mathrm{p}$ increase by $20 \%-30 \%$ at the 3 -hourly scale, while they are up to $60 \%$ larger when using the daily data. On the other hand, the projections of $90 \mathrm{p}$ changes at the 3-hourly scale over Spain and a large part of France and northern Italy are larger than at the daily scale.

The discrepancy between the analyses performed at different time scales is better clarified when examining the list of intense events identified with the daily and 3-hourly data. More than $50 \%$ (up to $70 \%$ over the NE domain) of the DJF intense events defined at 3-hourly time scale occur in days that are not identified as intense precipitation days according to the daily-based statistics (Fig. 4). On the other hand, the number of 3-hourly intense events occurring in days that are not defined as intense precipitation days is significantly reduced during summer (Fig. 5). Despite the model tendency to overestimate the described fraction (not shown) when compared to observations [TRMM Multisatellite Precipitation Analysis (TMPA); Huffman et al. 2007], this finding suggests that 3-hourly and daily events belong to distinct populations that share a common mean but different distributional properties on the upper tails. Moreover, this feature appears to be independent of the background climatological state because it remains substantially unaltered when comparing PRESENT to FUTURE (Fig. 4).

According to our findings, the conclusions we can draw about projected changes in intense precipitation (as identified by the 90p metric) are highly dependent on the data sampling frequency used in the analysis. The differences between the future projections computed at 
A) $\%$ of 3 h int. events outside the dd int. events in HIST djf

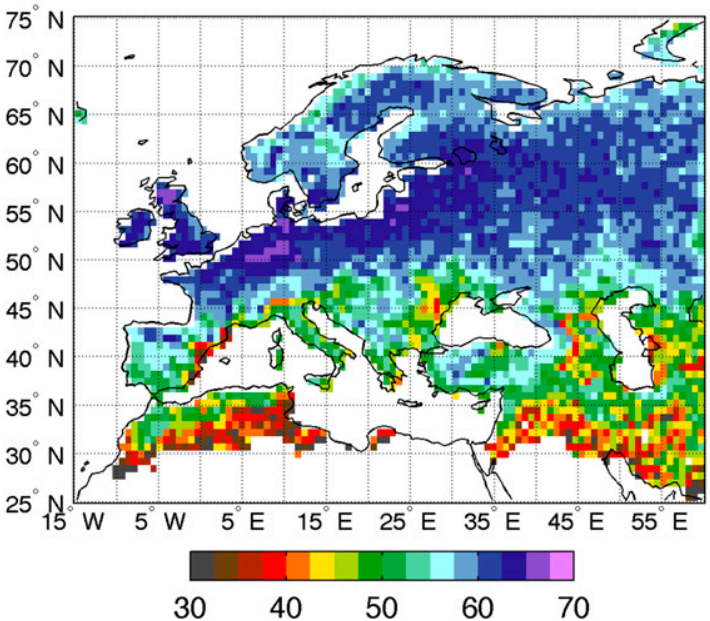

B) $\%$ of $3 \mathrm{~h}$ int. events outside the dd int. events in RCP85 djf

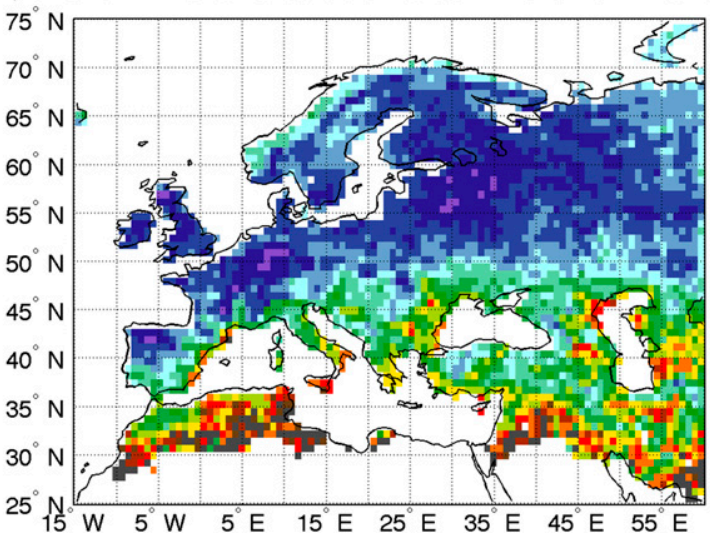

FIG. 4. Percentage of days with 3-hourly intense events that are not identified as intense based on the model outputs at the daily scale. Data are shown for DJF (see Fig. 5 for the summer distribution) for the (top) PRESENT (HIST) and (bottom) FUTURE (RCP85) runs. Units are \%.

the daily and at the 3-hourly time scale (Fig. 6a) are large and not uniform over our domain, with a $30 \%$ larger response in $90 \mathrm{p}$ for daily compared to 3-hourly time scales over the NE domain but a $20 \%$ smaller response over Spain. The statistical significance of the described differences was estimated via a bootstrap significance test (Scoccimarro et al. 2012). To explain this finding, we computed the difference between 3-hourly and daily projections in the number of precipitation time steps. The smaller projected changes of the 90p at the 3-hourly time scale over the NE domain (red patterns in Fig. 6a) is consistent with a broader spread in the precipitation distribution at the 3-hourly time scale in the projected future climate, compared to what is obtained using daily time series (red patterns in Fig. 6b), reflected in a projected increase of the dry days/dry hours ratio. The more pronounced $90 \mathrm{p}$ projected changes at the 3-hourly scale
A) \% of $3 \mathrm{~h}$ int. events outside the dd int. events in HIST jja

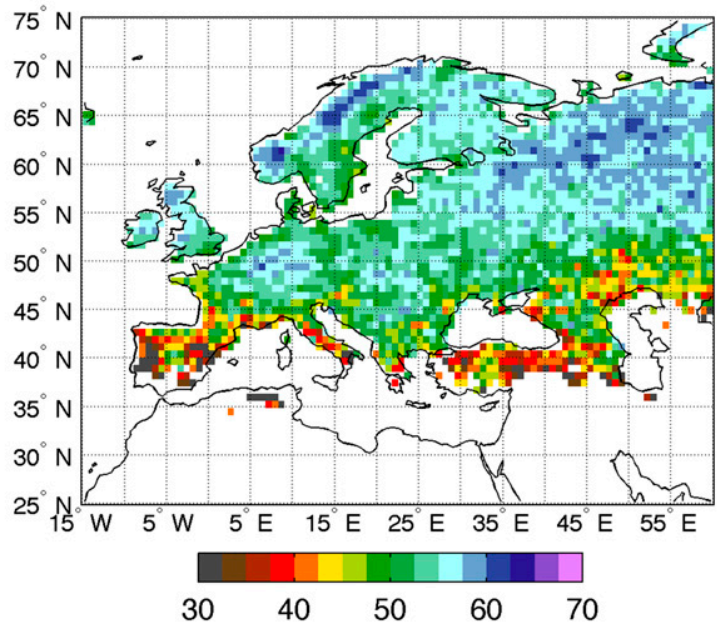

B) \% of $3 \mathrm{~h}$ int. events outside the dd int. events in RCP85 jja

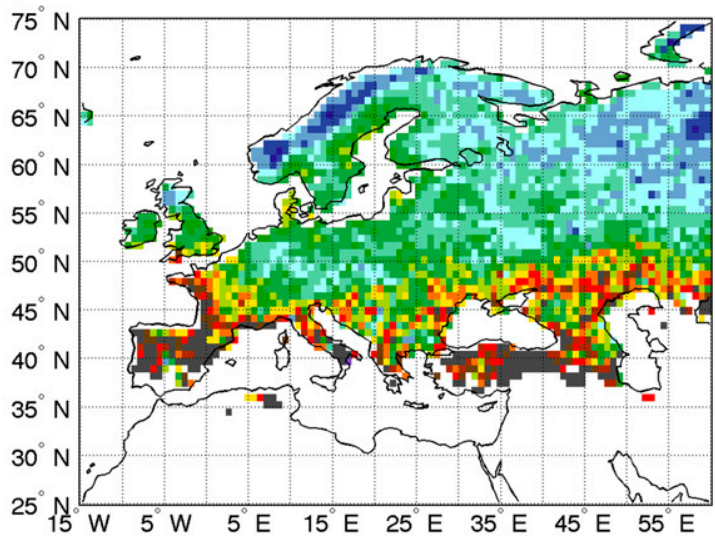

FIG. 5. As in Fig. 4, but for JJA.

over Spain (blue patterns in the top panel of Fig. 6) is consistent with a narrower projected precipitation distribution at the 3-hourly compared to the daily scale (blue patterns in the bottom panel of Fig. 6), and thus with a decrease of the dry days/dry hours ratio.

Interestingly, the more pronounced projected changes in the 90th percentile over the Mediterranean regions (blue patterns in Fig. 6a) at the 3-hourly scale are confirmed based on the 95th and 99th percentiles (see Fig. S2 in the supplemental material). This sensitivity analysis suggests that events responsible for intense and extreme events at the high frequency are the ones also defining the upper tails of the distribution at the daily frequency. On the other hand, the smaller projected changes at the 3-hourly time scale over the NE domain are less evident when focusing on the 95th and 99th percentiles. These results confirm that the 3-hourly extreme events are not participating in defining the upper tails of the precipitation distribution at the daily frequency over this region, as also supported by Fig. 4. 
A)

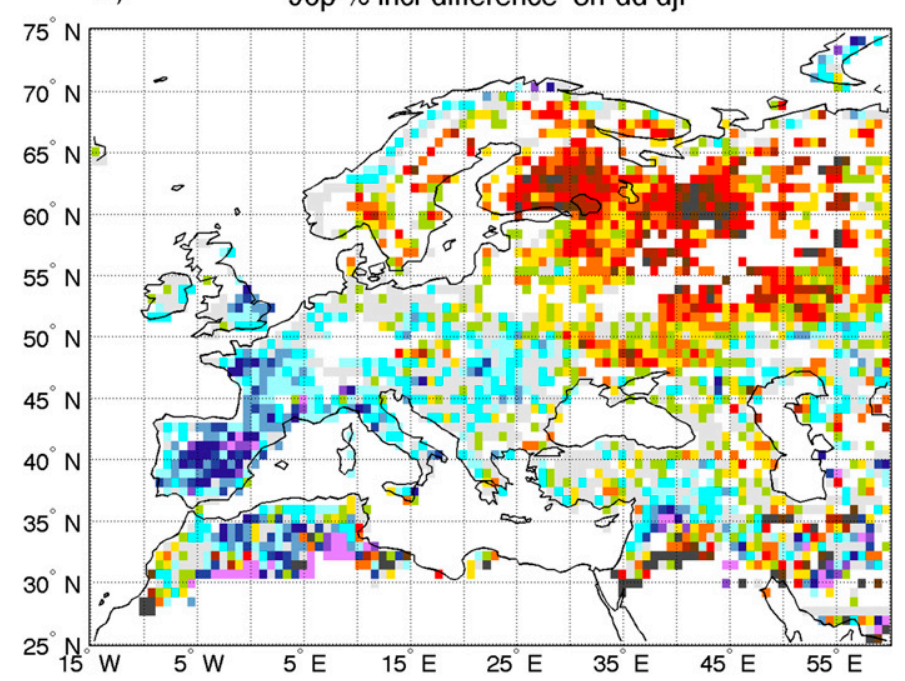

B)

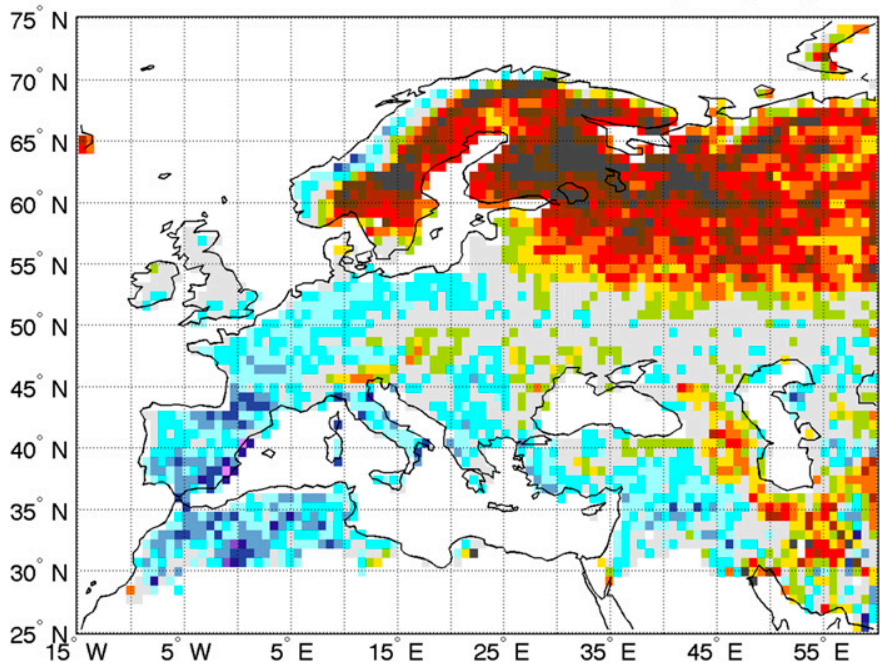

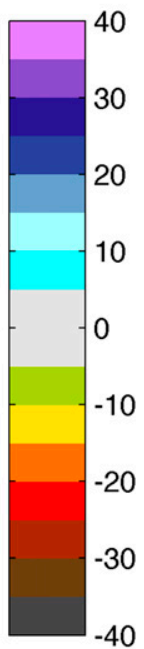

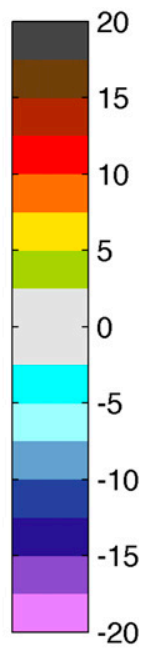

FIG. 6. (a) The differences in the estimation of the future changes in DJF 90th percentile (90p), when computed at the 3 -hourly scale, compared to the daily scale ( $3 \mathrm{~h}-\mathrm{dd})$. This map is obtained by subtracting the results in Fig. $3 \mathrm{~d}$ from those in Fig. 3c. White patterns over land indicate regions with seasonal precipitation lower than $0.2 \mathrm{~mm} \mathrm{day}^{-1}$ or regions where the differences are not statistically significant. (b) The differences between 3-hourly and daily future projections of the number of rainy time steps (defined as precipitation greater than $0.2 \mathrm{~mm} \mathrm{day}^{-1}$ ). Units are $\%$. White patterns over land indicate regions with seasonal precipitation lower than $0.2 \mathrm{~mm}_{\text {day }}{ }^{-1}$.

\section{Discussion and conclusions}

This study examined the projected changes in precipitation over Europe under a global warming scenario using daily and 3-hourly duration data. Results are based on a climate projection performed with the CMCC-CM model under radiative forcing conditions set by the RCP 8.5 scenario. While the mean properties of the precipitation distributions are independent of the analyzed temporal scale, significant differences in the projections of intense precipitation are found when considering alternative (i.e., 3-hourly vs daily) time windows for the accumulation of the precipitation field. This finding has implications for the inferences we make as to the potential impacts of intense precipitations on several fields because this analysis is usually carried out 
at the daily time scale (Pendergrass and Hartmann 2014), which is also due to the problematic assessment in subdaily rainfall satellite estimates (Liu and Allan 2012).

We found that the future spread of precipitation in time is more pronounced at the 3-hourly rather than daily scales over NE domain. This can be related to a reduced short-term (in time over a fixed grid point) precipitation activity in the future climate, leading to a future increase in the dry days/dry hours ratio when compared to the present period. In particular, over the NE domain (red patterns in Fig. 6) this is consistent with climate projections suggesting a general weakening of the storm track and a reduction in storm numbers in the northernmost part of the Atlantic Ocean and the Norwegian Sea. Here a reduction in storm numbers (Bengtsson et al. 2006; Solomon et al. 2007), together with an increase of precipitable water, could reduce the role played by intense fast-moving extratropical cyclones in determining heavy precipitation events changes in a warmer climate.

Consistently, climate models show an increase on the order of $40 \%-60 \%$ of the column integrated water content in the NE domain (more than 3 times what is projected over the southwestern part of Europe) at the end of the century for this scenario during winter (Scoccimarro et al. 2015). Moreover, because the fraction of the total precipitation (see Fig. S3 in the supplemental material) associated with snow dominates both total and heavy winter precipitation north of $55^{\circ}$ latitude, and since the intensity distribution of snowfall is important in terms of economic impacts (O'Gorman 2014), we decided to verify the fraction of heavy ( $>90 p$ ) precipitation events associated with snow both at 3-hourly and daily time scales. Over the NE domain and for the 3-hourly case, the fraction of heavy events associated with snow is higher both in PRESENT (Fig. 7a) and FUTURE (Fig. 7b) periods when compared to the daily scale. This suggests that snow is the major source of short duration intense precipitation events over this region. The amount of snow associated with heavy precipitation events is projected to decrease by between $20 \%$ and $50 \%$ (Fig. $7 \mathrm{c}$ ) over NE domain. Heavy precipitation events at the 3-hourly scale are more sensitive to snow changes, and are more affected by the projected snow reduction when compared to the daily results. This is also reflected in the 90 p projection differences shown in Fig. 6.

On the other hand, our findings suggest a future increase in intense precipitation events more pronounced at the subdaily time scale over Spain and over the western European seaboard (blue patterns in Fig. 6). Thus, at least over Spain and parts of western Europe, changes in short-duration precipitation extremes in
A) PRESENT fraction of snow in heavy events: $3 \mathrm{~h}$ - dd

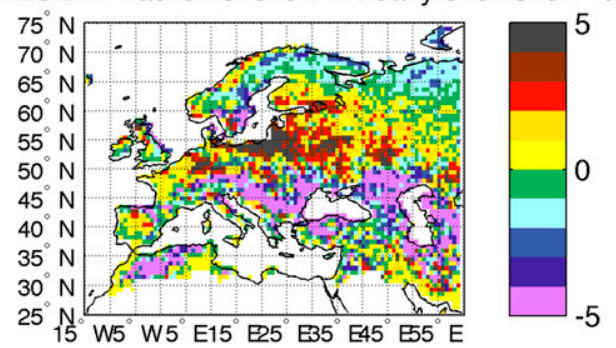

B) FUTURE fraction of snow in heavy events: $3 \mathrm{~h}$ - dd

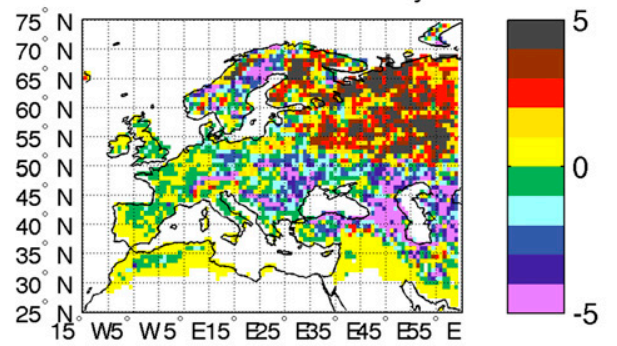

C) fraction of snow in 3h heavy events: FUTURE - PRESENT

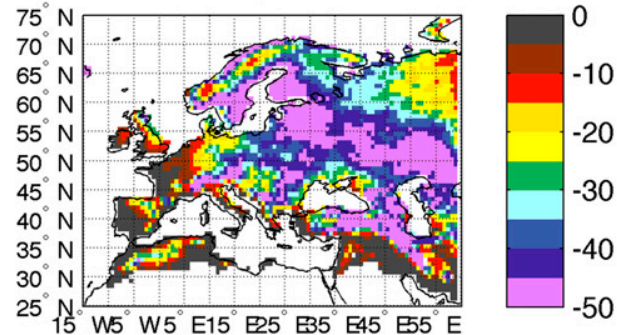

FIG. 7. Fraction of heavy precipitation $(>90 p)$ events associated with snow during DJF. (a) Difference between snow fraction in 3-hourly heavy events and daily heavy events in the PRESENT period $(3 \mathrm{~h}-\mathrm{dd})$. (b) As in (a), but for the FUTURE period. only. (c) Projection (FUTURE - PRESENT) of the fraction of snow in 3-hourly heavy events. Units are \%.

winter may well exceed expectations based on projections relying on daily time series analyses and the Clausius-Clapeyron relationship, in agreement with findings in Lenderink and van Meijgaard (2008). This is consistent with the resulting increase of the convective activity over the Mediterranean regions in the FUTURE climate, when compared to the PRESENT climate (Fig. 8). Since convective precipitation is critical in explaining the upper tail of the precipitation distribution over large parts of Europe, additional work is needed to establish to what extent the more pronounced 3-hourly intense events projection can be related to changes in future convective precipitation. A multimodel assessment is indeed necessary to corroborate our results: we hope this study highlights the importance of storing high-frequency (i.e., 3 hourly) model outputs, over long time periods, within international climate modeling 


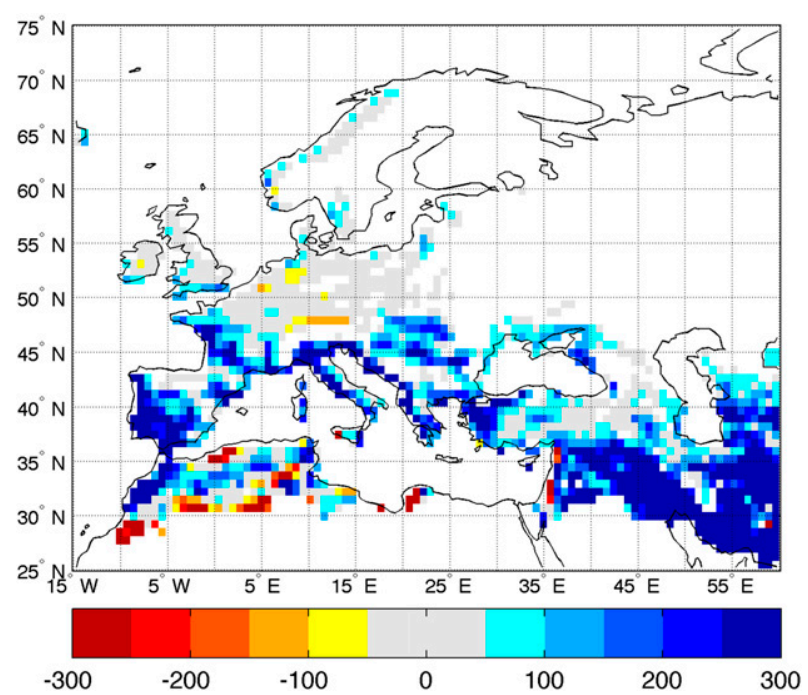

FIG. 8. Convective precipitation changes in the FUTURE period with regard to the PRESENT period during DJF. Units are \%. Only regions with convective precipitation fraction greater than $0.1 \%$ of the total precipitation are shown.

frameworks such as future coupled model intercomparison projects both at the global and the regional scale.

Acknowledgments. We gratefully acknowledge the support of Italian Ministry of Education, University and Research and Ministry for Environment, Land and Sea through the project GEMINA and the Italian Ministry for Environment, Land and Sea through the project NextDATA. The comments and suggestions by two anonymous reviewers are also acknowledged.

\section{REFERENCES}

Ban, N., J. Schmidli, and C. Schär, 2014: Evaluation of the convection-resolving regional climate modeling approach in decade-long simulations. J. Geophys. Res. Atmos., 119, 78897907, doi:10.1002/2014JD021478.

Bellucci, A., S. Gualdi, E. Scoccimarro, and A. Navarra, 2008: NAO-ocean circulation interactions in a coupled general circulation model. Climate Dyn., 31, 759-777, doi:10.1007/ s00382-008-0408-4.

_ coupled OAGCM initialized with oceanic reanalyses. Climate Dyn., 40, 1483-1497, 10.1007/s00382-012-1468-z.

Bengtsson, L., K. I. Hodges, and E. Roeckner, 2006: Storm tracks and climate change. J. Climate, 19, 3518-3543, doi:10.1175/ JCLI3815.1.

Bolvin, D. T., R. F. Adler, G. J. Huffman, E. J. Nelkin, and J. P. Poutiainen, 2009: Comparison of GPCP monthly and daily precipitation estimates with high-latitude gauge observations. J. Appl. Meteor. Climatol., 48, 1843-1857, doi:10.1175/ 2009JAMC2147.1.

Burt, S., 2005: Cloudburst upon Hendraburnick Down, 2005: The Boscastle storm of 16 August 2004. Weather, 60, 219-227, doi:10.1256/wea.26.05.
Chan, S. C., E. J. Kendon, H. J. Fowler, S. Blenkinsop, and N. M. Roberts, 2014a: Projected increases in summer and winter UK sub-daily precipitation extremes from high-resolution regional climate models. Environ. Res. Lett., 9, 084019, doi:10.1088/1748-9326/9/8/084019.

,,,,---- , and C. A. T. Ferro, 2014b: The value of high-resolution Met Office regional climate models in the simulation of multihourly precipitation extremes. J. Climate, 27, 6155-6174, doi:10.1175/JCLI-D-13-00723.1.

Chou, C., J. D. Neelin, C. Chen, and J. Tu, 2009: Evaluating the "rich-get-richer" mechanism in tropical precipitation change under global warming. J. Climate, 22, 1982-2005, doi:10.1175/ 2008JCLI2471.1.

Deser, C., R. Knutti, S. Solomon, and A. S. Phillips, 2012: Communication of the role of natural variability in future North American climate. Nat. Climate Change, 2, 775-779, doi:10.1038/nclimate1562.

Fichefet, T., and M. A. Morales-Maqueda, 1999: Modeling the influence of snow accumulation and snow-ice formation on the seasonal cycle of the Antarctic sea-ice cover. Climate Dyn., 15, 251-268, doi:10.1007/s003820050280.

Fogli, P. G., and Coauthors, 2009: INGV-CMCC Carbon (ICC): A carbon cycle Earth system model. CMCC Tech. Rep. 61,30 pp. [Available online at http://www.cmcc.it/publications/rp0061ingv-cmcc-carbon-icc-a-carbon-cycle-earth-system-model.]

Gent, P. R., and J. C. McWilliams, 1990: Isopycnal mixing in ocean circulation models. J. Phys. Oceanogr., 20, 150-155, doi:10.1175/1520-0485(1990)020<0150:IMIOCM>2.0.CO;2.

Giorgi, F., E.-S. Im, E. Coppola, N. S. Diffenbaugh, X. J. Gao, L. Mariotti, and Y. Shi, 2011: Higher hydroclimatic intensity with global warming. J. Climate, 24, 5309-5324, doi:10.1175/ 2011JCLI3979.1.

Gualdi, S., E. Scoccimarro, and A. Navarra, 2008: Changes in tropical cyclone activity due to global warming: Results from a high-resolution coupled general circulation model. J. Climate, 21, 5204-5228, doi:10.1175/2008JCLI1921.1.

Hagos, S., L. R. Leung, Q. Yang, C. Zhao, and J. Lu, 2015: Resolution and dynamical core dependence of atmospheric river frequency in global model simulations. J. Climate, 28, 2764 2776, doi:10.1175/JCLI-D-14-00567.1.

Hanel, M., and T. A. Buishand, 2010: On the value of hourly precipitation extremes in regional climate model simulations. J. Hydrol., 393, 265-273, doi:10.1016/j.jhydrol.2010.08.024.

Hegerl, G. C., F. W. Zwiers, P. A. Stott, and V. V. Kharin, 2004: Detectability of anthropogenic changes in annual temperature and precipitation extremes. J. Climate, 17, 3683-3700, doi:10.1175/1520-0442(2004)017<3683:DOACIA > 2.0.CO;2. , and Coauthors, 2007: Understanding and attributing climate change. Climate Change 2007: The Physical Science Basis, S. Solomon et al., Eds., Cambridge University Press, 663-745.

Heinrich, G., and A. Gobiet, 2011: The future of dry and wet spells in Europe: A comprehensive study based on the ENSEMBLES regional climate models. Int. J. Climatol., 32, 1951-1970, doi:10.1002/joc.2421.

Huffman, G. J., and Coauthors, 2007: The TRMM Multisatellite Precipitation Analysis (TMPA): Quasi-global, multiyear, combined-sensor precipitation estimates at fine scales. J. Hydrometeor., 8, 38-55, doi:10.1175/JHM560.1.

Jones, H., R. S. Westra, and A. Sharma, 2010: Observed relationships between extreme sub-daily precipitation, surface temperature, and relative humidity. Geophys. Res. Lett., 37, L22805, doi:10.1029/2010GL045081. 
Kendon, J. E., and Coauthors, 2014: Heavier summer downpours with climate change revealed by weather forecast resolution model. Nat. Climate Change, 4, 570-576, doi:10.1038/ nclimate2258.

Kharin, V. V., and F. W. Zwiers, 2000: Changes in the extremes in an ensemble of transient climate simulations with a coupled atmosphere-ocean GCM. J. Climate, 13, 3760-3788, doi:10.1175/1520-0442(2000)013<3760:CITEIA > 2.0.CO;2.

,-- X. Zhang, and G. C. Hegerl, 2007: Changes in temperature and precipitation extremes in the IPCC ensemble of global coupled model simulations. J. Climate, 20, 1419-1444, doi:10.1175/JCLI4066.1.

Kiktev, D., J. Caesar, L. V. Alexander, H. Shiogama, and M. Collier, 2007: Comparison of observed and multimodeled trends in annual extremes of temperature and precipitation. Geophys. Res. Lett., 34, L10702, doi:10.1029/ 2007 GL029539.

Lavers, D. A., R. P. Allan, G. Villarini, B. Lloyd-Hughes, D. J. Brayshaw, and A. J. Wade, 2013: Future changes in atmospheric rivers and their implications for winter flooding in Britain. Environ. Res. Lett., 8, 034010, doi:10.1088/1748-9326/ 8/3/034010

Lenderink, G., and E. van Meijgaard, 2008: Increase in hourly precipitation extremes beyond expectations from temperature changes. Nat. Geosci., 1, 511-514, doi:10.1038/ngeo262.

Lin, S. J., and R. B. Rood, 1996: Multidimensional flux-form semiLagrangian transport schemes. Mon. Wea. Rev., 124, 2046-2068, doi:10.1175/1520-0493(1996)124<2046:MFFSLT>2.0.CO;2.

Liu, C., and R. P. Allan, 2012: Multisatellite observed responses of precipitation and its extremes to interannual climate variability. J. Geophys. Res., 117, D03101, doi:10.1029/2011JD016568.

Madec, G., P. Delecluse, M. Imbard, and C. Levy, 1998: OPA 8.1 ocean general circulation model reference manual. IPSL Note du Pole de Modelisation 11, 91 pp.

Meehl, G. A., and S. Bony, 2012: Introduction to CMIP5. WCRP Coupled Model Intercomparison Project-Phase 5: CLIVAR Exchanges, No. 56, Vol. 15, No. 2, International CLIVAR Project Office, Southampton, United Kingdom, 4-5. [Available online at http://www.clivar.org/node/236.]

_ J. M. Arblaster, and C. Tebaldi, 2005: Understanding future patterns of increased precipitation intensity in climate model simulations. Geophys. Res. Lett., 32, L18719, doi:10.1029/ 2005 GL023680.

—, C. Covey, T. Delworth, M. Latif, B. McAvaney, J. F. B. Mitchell, R. J. Stouffer, and K. E. Taylor, 2007: The WCRP CMIP3 multimodel dataset: A new era in climate change research. Bull. Amer. Meteor. Soc., 88, 1383-1394, doi:10.1175/ BAMS-88-9-1383.

Min, S.-K., X. Zhang, F. W. Zwiers, P. Friederichs, and A. Hense, 2009: Signal detectability in extreme precipitation changes assessed from twentieth century climate simulations. Climate Dyn., 32, 95-111, doi:10.1007/s00382-008-0376-8.

Molnar, P., S. Fatichi, L. Gaál, J. Szolgay, and P. Burlando, 2015: Storm type effects on super Clausius-Clapeyron scaling of intense rainstorm properties with air temperature. Hydrol. Earth Syst. Sci., 19, 1753-1766, doi:10.5194/hess-19-1753-2015.

Nikulin, G., E. Kjellstrom, U. Hansson, G. Strandberg, and A. Ullerstig, 2011: Evaluation and future projections of temperature, precipitation and wind extremes over Europe in an ensemble of regional climate simulations, Tellus, $\mathbf{6 3 A}, 41-55$, doi:10.1111/j.1600-0870.2010.00466.x.

Nordeng, T. E., 1994: Extended versions of the convective parametrization scheme at ECMWF and their impact on the mean and transient activity of the model in the tropics. ECMWF Research Department Tech. Memo. 206, 41 pp.

O'Gorman, P. A., 2014: Contrasting responses of mean and extreme snowfall to climate change. Nature, 512, 416-418, doi:10.1038/ nature 13625 .

Pendergrass, A. G., and D. L. Hartmann, 2014: Two modes of change of the distribution of rain. J. Climate, 27, 8357-8371, doi:10.1175/JCLI-D-14-00182.1.

Rajczak, J., P. Pall, and C. Schär, 2013: Projections of extreme precipitation events in regional climate simulations for $\mathrm{Eu}-$ rope and the Alpine region. J. Geophys. Res. Atmos., 118, 3610-3626, doi:10.1002/jgrd.50297.

Riahi, K., and Coauthors, 2011: RCP 8.5-A scenario of comparatively high greenhouse gas emissions. Climatic Change, 109, 33-57, doi:10.1007/s10584-011-0149-y.

Roeckner, E., and Coauthors, 2003: The atmospheric general circulation model ECHAM5. Part I: Model description. MPI Rep. 349, 127 pp.

_ , and Coauthors, 2006: Sensitivity of simulated climate to horizontal and vertical resolution in the ECHAM5 atmosphere model. J. Climate, 19, 3771-3791, doi:10.1175/JCLI3824.1.

Roullet, G., and G. Madec, 2000: Salt conservation, free surface, and varying levels: A new formulation for ocean general circulation models. J. Geophys. Res., 105, 23 927-23 942, doi:10.1029/ 2000JC900089.

Schindler, A., A. Toreti, M. Zampieri, E. Scoccimarro, S. Gualdi, S. Fukutome, E. Xoplaki, and J. Luterbacher, 2015: On the internal variability of simulated precipitation. J. Climate, 28, 3624 3630, doi:10.1175/JCLI-D-14-00745.1.

Scoccimarro, E., and Coauthors, 2011: Effects of tropical cyclones on ocean heat transport in a high-resolution coupled general circulation model. J. Climate, 24, 4368-4384, doi:10.1175/ 2011JCLI4104.1.

— - S. Gualdi, and A. Navarra, 2012: Tropical cyclone effects on Arctic sea ice variability. Geophys. Res. Lett., 39, L17704, doi:10.1029/2012GL052987.

,-- A. Bellucci, M. Zampieri, and A. Navarra, 2013: Heavy precipitation events in a warmer climate: Results from CMIP5 models. J. Climate, 26, 7902-7911, doi:10.1175/JCLI-D-12-00850.1.

,,,,---- and,- 2015 : Heavy precipitation events over the Euro-Mediterranean region in a warmer climate: Results from CMIP5 models. Reg. Environ. Change, doi:10.1007/ s10113-014-0712-y, in press.

Seager, R., N. Naik, and L. Vogel, 2012: Does global warming cause intensified interannual hydroclimate variability? J. Climate, 25, 3355-3372, doi:10.1175/JCLI-D-11-00363.1.

Smiatek, G., H. Kunstmann, R. Knoche, and A. Marx, 2009: Precipitation and temperature statistics in high-resolution regional climate models: Evaluation for the European Alps. J. Geophys. Res., 114, D19107, doi:10.1029/2008JD011353.

Solomon, S., D. Qin, M. Manning, Z. Chen, M. Marquis, K. Averyt, M. M. B. Tignor, and H. L. Miller Jr., 2007: Climate Change 2007: The Physical Science Basis. Cambridge University Press, 996 pp.

Stocker, T. F., and Coauthors, Eds., 2013: Climate Change 2013. The Physical Science Basis. Cambridge University Press, $1535 \mathrm{pp}$.

Taylor, K. E., R. J. Stouffer, and G. A. Meehl, 2012: An overview of CMIP5 and the experiment design. Bull. Amer. Meteor. Soc., 93, 485-498, doi:10.1175/BAMS-D-11-00094.1.

Tebaldi, C., K. Hayhoe, M. J. Arblaster, and G. A. Meehl, 2006: Going to the extremes: An intercomparison of modelsimulated historical and future changes in extreme events. Climatic Change, 79, 185-211, doi:10.1007/s10584-006-9051-4. 
Tiedtke, M., 1989: A comprehensive mass flux scheme for cumulus parametrization in large-scale models. Mon. Wea. Rev., 117, 17791800, doi:10.1175/1520-0493(1989)117<1779:ACMFSF > 2.0.CO;2.

Toreti, A., and Coauthors, 2013: Projections of global changes in precipitation extremes from Coupled Model Intercomparison Project phase 5 models. Geophys. Res. Lett., 40, 4887-4892, doi:10.1002/ grl.50940.

Trenberth, K. E., A. Dai, R. Rasmussen, and D. Parsons, 2003: The changing character of precipitation. Bull. Amer. Meteor. Soc., 84, 1205-1217, doi:10.1175/BAMS-84-9-1205.
Valcke, S., Ed., 2006: OASIS3 user guide (prism_2-5). PRISMSupport Initiative Rep. 3, 64 pp. [Available online at www.prism. enes.org/Publications/Reports/oasis3_UserGuide_T3.pdf.]

Vichi, M., and Coauthors, 2011: Global and regional ocean carbon uptake and climate change: Sensitivity to an aggressive mitigation scenario. Climate Dyn., 37, 19291947, doi:10.1007/s00382-011-1079-0.

Wetherald, R. T., and S. Manabe, 1999: Detectability of summer dryness caused by greenhouse warming. Climatic Change, 43, 495-511, doi:10.1023/A:1005499220385. 